\title{
Moral Distress Entangled: Patients and Providers in the COVID-19 Era
}

\author{
Sarah Vittone $^{1}$ (D) $\cdot$ Claudia R. Sotomayor $^{2}$ (D)
}

Accepted: 15 March 2021 / Published online: 28 March 2021

(c) The Author(s), under exclusive licence to Springer Nature B.V. 2021

\begin{abstract}
Moral distress is defined as the inability to act according to one's own core values. During the COVID-19 pandemic, moral distress in medical personnel has gained attention, related to the impact of pandemic-associated factors, such as the uncertainty of treatment options for the virus and the accelerated pace of deaths. Measures to provide aid and mitigate the long-term pandemic effect on providers are starting to be designed. Yet, little has been said about the moral distress experienced by patients and the relational and additive effect on provider moral distress. Pandemic-associated factors affecting moral distress in patients include the constraining effects of isolation on spiritual and religious traditions as well as the intentional separation of patients from their families. This paper will explore the idea that patients are suffering their own moral distress and further how this impacts the intensity of moral distress experienced by the providers-nurses and physicians. The paucity of research in this area with the implications on patient's distress, decision making, and distress experienced by providers compels further investigation and analysis.
\end{abstract}

Keywords Emotional distress · Moral distress - COVID $19 \cdot$ Patient distress · Pandemic related distress $\cdot$ Ethics $\cdot$ End of life

\section{Introduction}

With the current health advisories and procedures in place, people are developing unusual levels of emotional distress (Zhang et al. 2020). Emotional distress is defined as the experience of negative affect, such as anxiety, in the context of a physiological stress response. Emotional stress commonly occurs when an individual perceives that

Claudia R. Sotomayor

crs145@georgetown.edu

1 School of Nursing, Pellegrino Center of Clinical Bioethics and Georgetown University Medical Center, Washington, DC, USA

2 Internal Medicine, Pellegrino Center of Clinical Bioethics and Georgetown University Medical Center, Washington, DC, USA 
he or she does not have adequate personal resources to meet situational demands effectively (Mendelson 2013). Pandemic-related issues such as social distancing, isolation and quarantine, as well as the social and economic fallout from these measures can trigger emotional distress (Mamun \& Griffiths 2020). Under normal circumstances, patients often suffer from emotional distress due to the anxiety of a diagnosis or procedure, the pain or struggles that come along different diseases and treatments. It has been described that emotional distress - as a broad term — can be triggered by exposure to fear, grief, frustration, information overload, and worry (Lamberson 2016). During COVID-19 times, this emotional distress in patients escalates to new levels, and now we see that our patients are adding moral distress to their emotional distress.

In contrast to emotional distress, moral distress is defined as the response to an inability to act according to core values. The term was first introduced by Jameton (1984) in his book on nursing ethics, where he elucidated the concept of moral distress in terms of the way in which institutional policies and practices can constrain nurses from doing what they believe is morally right. The conversation on moral distress has since expanded to include all medical personnel (Ulrich \& Grady 2018).

Moral distress is generally considered to be different to emotional distress (Lamberson 2016; McCarthy \& Deady 2008), but in response to the pandemic we are seeing an entanglement of both forms of distress. This becomes evident when moral distress is expressed as painful emotions and feelings and as mental anguish. Similarly, there is evidence that morally distressed persons report feelings of anger, frustration, resentment, sorrow, anxiety, helplessness or powerlessness, compromised integrity, shame, embarrassment, grief, heartache, misery, pain, sadness, dread, disgust, and anguish (Willis 2015/14).

During the COVID-19 pandemic, moral distress in medical personnel is gaining attention, and measures to provide aid and countermeasures of its long-term effect are being designed (Greenberg, Docherty, Gnanapragasam, \& Wessely 2020). However, little is being said about the patient and the patient's families' experience. The SARSCOV-2 virus transmission mitigating strategy for healthcare facilities of separating families from their loved ones has affected all patients, not just those with a positive diagnosis. How has this isolated environment affected patients? Can a patient suffer moral distress? This paper will explore the idea that patients are suffering a pandemic associated moral distress and further how this has an impact on the intensity of moral distress experienced by the providers - nurses and physicians. As a result, strategies to proactively detect and address the entangled moral distress by a team of psychologists, ethicists, and various teams among the hospital should be in place.

\section{Cases $^{1}$}

\section{Case A}

1. Mrs. Smith is a 70-year-old female from out of state, Catholic, married for 50 years. She became a patient of this institution in 2019 when she received a

1 The details of these cases have been altered to protect the patient and family identity. 
transplant. She came regularly for follow-ups. She always came with her husband, who was always holding her hand. In March, she presented to her appointment with anosmia, fever, cough and myalgias. She was tested for COVID-19, and was positive. She was admitted to the hospital to a special COVID-19 unit, where she was isolated. Shortly after her admission she developed shortness of breath and was intubated. At the same time, her husband developed symptoms, so he was tested for COVID-19 and was being isolated outside the hospital. Mrs. Smith rapidly declined, and the medical team decided that pursuing more treatment was futile. They decided to have a family meeting via zoom. During the family meeting, Mr. Smith agreed to the DNR order. Mrs. Smith died the next day.

\section{Case B}

2. Ms. Kenba is a 66-year-old mother and widow with a new diagnosis of stage 4 cancer. She was admitted for diagnostics and initial treatment. She is COVID$19+$, afebrile with no respiratory symptoms. She has had many web calls and is on the phone frequently with her family. She has not slept or eaten well in the last few days. Jana Ho, a Eucharistic Minister from Ms. Kenba's parish, calls to ask the nurse for permission to bring the Eucharist to the hospital for Ms. Kenba. The call is transferred up the administrative chain. Ms. Ho is frustrated to be kept away, as is Ms. Kenba to be unable to practice her faith. Priests are not making their regular rounds and the Eucharistic Minister is told that she cannot visit Ms. Kenba. The nurse is sad, feels stressed, and asks Ms. Kenba if she would like to pray with her.

\section{Case C}

3. Mrs. Garcia is an 89-year-old mother and widow with new onset renal failure. She knows this renal failure was likely the adverse result of her medication for osteoporosis. She is COVID-19 negative. Mrs. Garcia, who has decision making capacity, is fearful of the dialysis planned to start tomorrow. Mrs. Garcia is tearful and desperate for her daughter to be with her today. The web-based call with her daughter leaves her more distressed. Mrs. Garcia was hardly able to see her phone due to the tears in her eyes, and could not hear well; all this further highlighting that technology was a very poor substitute for the physical presence of her daughter. Her daughter is polite and requests a brief visit tomorrow morning. There has been a local increase in reported COVID-19 cases, so the policy stands-no visitors. The patient begs the hospitalist for a visit from her daughter. 


\section{The Patient's Experience}

Case A is very straightforward at a first glance. A patient becomes gravely ill; a family meeting is held resulting in a DNR order and the patient passes away. There is no apparent ethical dilemma. However, this case was fraught with moral distress. The medical team expressed their distress in knowing that Mr. and Mrs. Smith were always together and now they had to be separated, when she needed him the most. Efforts were made to see if they could bring Mr. Smith to say goodbye, but the policies and procedures in place and the hospital setting did not allow for that reunion. The medical personnel also tried to facilitate a priest for the provision of the sacrament of Anointing of the Sick, but because she was isolated, they could not offer it. Medical personnel noted a level of distress never seen before in the patient and her husband. Ethics was consulted, and it was concluded that the patient and her husband were suffering from moral distress. This case triggered many conversations, and now at this hospital, chaplains and family may visit patients when they are at the end of life.

This case also highlights the fear of dying while alone, which is nearly universal. In each culture, death is associated with rituals and customs to help people with the grieving process. Factors associated with the pandemic complicate the practice of these rituals. The lack of communal death-patients and families together-affects not only the patient but also the family. This inability to engage in traditions that support the grieving process can make it difficult to cope. Saying goodbye is an important step to grieve, but on this occasion, saying goodbye is difficult. An approved visit at the end of life becomes a complex compassionate moment with strict procedures which may or may not include a touch of hand or an embrace so desperately desired. Funerals are also an important part of the grieving process, yet unfortunately friends and family cannot gather to hold a funeral, memorial, or another religious service. After all these missed steps, people may feel regret because they could not be present to support their loved one in their final moments (Cherry 2020).

Case B brings forward the issue of moral distress for patients who are not at the end of life, but need to practice their faith. The patient and her family, as devout Catholics, firmly believed that they needed to receive communion because participating in the sacraments is imperative to live in communion with God (De La Soujeole 2010). The church recognizes the constraints on the practice of the sacraments, and Bishops have dispensed the faithful from their obligation to attend mass (United States Conference of Catholic Bishops 2020). Regardless, for this patient, the inability to practice her faith, and participate in sacraments created a state of moral distress. Moreover, the patient can feel morally distressed when their cultural/religious beliefs are challenged. For example, for some Muslims, male doctors may have to communicate through a spouse if the patient is female (Attum, Waheed, \& Shamoon 2020), but in an isolated room this practice, though not impossible, may be difficult to achieve in emergency cases. Regardless of the religious belief, when a patient is experiencing an inability to participate in their own traditions and rituals deemed morally necessary for their salvation or transcendence due to the COVID-19 policies and procedures in place, then they are experiencing moral distress because they 
cannot act according to their core values. In this case the struggle with a terminal diagnosis, reflecting on the lived life and the hope for future are all key to moral identity, is left unaddressed and unmet. In this case, the nurse with an obligation to support the spiritual needs of the patient is ready. Many professional nurses and physicians are hesitant and unprepared to address the spiritual needs of their patients (Balboni, Sullivan, \& Enzinger 2014).

Case $\mathrm{C}$ presents a different unintended effect of the new hospital policies. While all patients and families - regardless of the diagnoses-experience emotional distress based on their vulnerabilities, it is the isolation of patients at hospitals and other fears that can entangle the emotional distress with moral distress. Traditionally, we have developed a sense of duty to take care of a family member who is sick, the patient on the other hand receives comfort and support from family members and people from his/her community. This support plays an important role in the healing process, unfortunately the isolation policies in each hospital is increasing the feelings of apprehension, uneasiness, uncertainty or dread about possible future events and the ability to deal with the events when alone and isolated. Communication and the shared decision-making process is also challenged because it is becoming very difficult for family members and surrogate decision makers to understand the full picture when they cannot be at bedside. In case $\mathrm{C}$, the patient is unable to create for herself, while alone, that moral stability and requires the physical presence, the human connection with her family. The hospitalist feels helpless as witness to this suffering. She seeks an administrative approval for the visit, but these are only approved for the dying. The physician is unable to act for her patient to meet these needs, while knowing the isolation is necessary as the virus continues to rage in the community.

\section{Moral Distress in Medical Personnel: “Impact of Pandemic Associated Factors"}

It is the nature of the clinician-patient relationship to focus on the good of the patient. Pellegrino defined these goods as the biomedical good, the patient's perception of his or her good, the good of the patient as a human being and the spiritual good of the patient (Pellegrino \& Thomasma 1988). The moral and professional obligation to address this spiritual or moral good is hindered by these pandemic associated factors. The provider's moral distress is now entangled in the patient's suffering. The patient's emotional and specifically moral suffering may be perceived by the providers as emotional abandonment. In most instances, one could always count on the family to comfort and console the patient once the medical team steps out of the room. This lack of family presence, although intentional and becoming more customary as time goes by, is strikingly still unfamiliar. Further this isolation impacts the ideal patient- or family-centered care model. The technology-assisted interaction now offered for patients and their families may be acceptable, but it is ultimately still lacking. Patients continue to yearn to have their loved-ones physically close to them. Every terminal diagnosis disclosed or change in plan of care 
now through virtual means, continues to stress the patient who is strangely alone even in the presence of the nurses and physicians.

Constraints on providers' agency to act or to facilitate robust patient-family centered decision making, and may result in moral distress-affecting the plan of care for patients under their supervision or assignment. Addressing these constraints for nurses within the healthcare team has been the focus of much discussion in the literature, including strategies for resolving distress and strengthening resilience (Rushton 2016). According to Fourie (2017), there are three independent values relevant to moral distress in health care- the well-being of the patient, the well-being of the professional and the distribution of the moral distress among the professionals. We suggest that in the current climate the moral distress is also shared by the patient. Moral distress based in constraint-distress occurs when the medical professional knows with some certainty the morally correct action to take but there is something -a constraint or obstacle- which prevents them from being able to take the morally correct action. Currently, the medical team is constrained by the circumstances created by the virus itself: the urgency of the situation, the accelerated pace of the deaths, the lack of personal protective equipment, etc. Standard of care is exhausted and this constrains experts in practice. Fourie suggests a broader definition to include uncertainty as an added defining factor for moral distress. Uncertainty-distress is present where actions are morally unclear, as our response to the virus itself: the dynamic nature of the virus, the uncertainty regarding treatments, the fear of failure, helplessness, the disconnected family uncertain about their decisions and uncertainty in the future. The additive aspects of both contraining and uncertainty impacts the overall moral distress experience in this evolving pandemic. These with the additional chaotic pace of information, decision making and crisis planning are additive to an experience of unfamiliar moral distress.

\section{The Role of Bioethics}

Bioethicists as clinical ethics consultants provide a skilled response in times of uncertainty and conflict, which lead to moral distress with interventions to enhance individual and collective moral resilience. Ethics consultants in addition to their role in facilitating decision making (when the plan of care is complex, when there is uncertainty about values) offer aid in addressing moral distress through strengthening moral resilience (American Society for Bioethics and Humanities 2009).

The way that ethicists help build moral resilience is by implementing a multifaceted approach based in mindfulness and self-care as well as interventions to support and restore ethical competence (Rushton 2015). Ethical competence during this pandemic may be supported in two parts: through education and through focused reflection. First, ethics education may be more necessary in these unusual times. We continue to stress our common ethical understanding of the core principles: autonomy, beneficence, nonmaleficence and justice (Beauchamp \& Childress 2019). Due to the current pandemic experience we add in additional considerations of solidarity and reciprocity. Solidarity is a respect for the common good, coming together (Ter Meulen 2016; Meulen 2018; Velazquez, Andre, Shanks, \& Meyer 2018; Prainsack 
\& Buyx 2017). The clinical team is depended on to be more physically present and readily available. The efforts to focus on the goods of the patient depend on the extension of the relationship, the common collective struggle we share in the pandemic. Additionally, Halbesleben (2006), recognized the social exchange model of burnout, suggesting that patient stressors may predict perceived reciprocity and subsequent burnout in physicians. Reciprocity and the relational aspects between providers and patients, organizations and their employees, etc. affect the experience and may, we believe in this pandemic state, affect moral distress.

All of this is applied within our practical ethics approach. Our core ethics continues to guide even in time of challenge, as we plan and prepare for resource allocation and crisis management (Sulmasy 2020). As we continue to experience unrelenting change and expectations continue to pivot, distress may be unresolved. Professionals in moral distress need focused reflection to process their experiences. Ethics consultants aid in the processing of expressed distress and may clarify constraints and perceived breaches in ethical principles or professional obligations affecting practice. The ethics consultants help not only by using their expertise in ethical analysis and in their core competencies of empathetic listening and summarizing, but they also help staff by reviewing and reviving personal values, suggesting proactively how to be more self-aware and to reframe motivation and direction in their professional practice considering the challenges ahead. Ethics is a common meeting ground to blend together experiences_-rebuilding resilience.

\section{Morally Entangled}

We expect moral distress at a heightened level, and more frequently reported as this pandemic is, as often said, unprecedented. The relational aspect of patients with their nurses and physicians clearly lends itself to this moral entanglement. This unfamiliar moral distress is a response to the unrelieved moral suffering of patients. There is no fix for the isolation, the constraint is unrelenting but necessary. Further, the different layers of distress that are present in each case, and the effects had on both patients and clinicians, make it clear that moral distress has elements of emotional distress. If the distress prolongs or escalates and the individual experiences a severe event where the moral violation results in psychological, spiritual, behavioral, and social impact, individuals may suffer from moral injury (Roycroft, Wilkes, Pattani, Fleming, \& Olsson-Brown 2020). Moral injury is a more extreme form of moral distress that increases in situations where there is a perceived violation of one's personal integrity. They may also feel a moral residue, a feeling of shame, guilt, or regret, and a perception of moral deficiency. It is important to acknowledge these issues and take timely action because ultimately moral distress can cause burnout, a sense of disillusion for the vocation to serve in the medical field that can lead clinicians to leave their profession, and in extreme circumstances post-traumatic stress disorder and other mental issues (Rushton, Doerries, Greene, \& Geller 2020). This is why a continued collaboration between psychologists, ethicists, and hospital leadership is necessary. Attention and awareness to the issues, facilitating ethical complexities, and supporting moral integrity through resilience, reflection and facing obligations 
in our common ethical manner are best practice in addressing the entangled moral distress.

As a practical response to Case A, the ethics consultant facilitated the family meeting, listening, coaching and supporting the delicate aspects addressed. The resolution of this case also led to a follow up meeting with the team involved for both moral and emotional processing. In Case B, a supportive approach was used to validate the experience of the patient and the Eucharistic minister. The nurse addressing the spiritual needs of the patient was validated by the ethics consultant in this unexpected need she was willing and able to address. In Case $\mathrm{C}$, the ethics consultant was able to support an administrative consideration for a compassionate visit. These important opportunities for policies to be adapted for individual patients will be another area for considered reflection once family presence has been restored.

The moral distress of patients is a novel phenomenon-when persons are unexpectedly limited in their moral choices or rituals and traditions, especially in a western society where autonomy is highly regarded. The pandemic associated intentional isolation of patients has led to this unfamiliar strain beyond the emotional to an identified moral experience. The long-term consequences being foreseen now will motivate how we adapt and respond in these isolating times. The recognition of this entangled moral distress validates our experience and brings up one of the most beautiful aspects of humanity: its solidarity. The acknowledgment and acceptance of this situation could be the unifying factor that we need to move forward as a medical community. The paucity of research in this area with the implications on patient's distress, decision making and distress experienced by providers compels further investigation and analysis. Currently, creative ways to bridge the isolation, to bend the policy, and to look for new ways to return to our normal brotherly compassion are being developed. These times could be an opportunity to review our raison $d$-etre and reset our clinical and ethical professional compass.

\section{References}

American Society for Bioethics and Humanities. (2009). Improving competencies in clinical ethics consultation: An education guide. American Society for Bioethics and Humanities.

Attum, B., Waheed, A., \& Shamoon, Z. (2020). Cultural competence in the care of Muslim patients and their families [Updated 2020 Feb 17]. StatPearls. Retreived March 24, 2021, from https://www.ncbi. nlm.nih.gov/books/NBK499933/.

Balboni, M. J., Sullivan, A., Enzinger, A. C., et al. (2014). Nurse and physician barriers to spiritual care provision at the end of life. Journal of Pain and Symptom Management, 48(3), 400-410. https://doi. org/10.1016/j.jpainsymman.2013.09.020.

Beauchamp, T., \& Childress, J. (2019). Principles of biomedical ethics. (8th ed.). Oxford University Press.

Cherry, K. (2020). Understanding grief in the age of the COVID-19 pandemic. Retreived March 24, 2021, from https://www.verywellmind.com/understanding-grief-in-the-age-of-the-covid-19-pande mic-4801931.

De La Soujeole, B. (2010). The importance of the definition of sacraments as signs. In R. Hütter \& M. Levering (Eds.), Ressourcement Thomism: Sacred doctrine, the sacraments, and the moral life. (pp. 127-135). Catholic University of America Press. https://doi.org/10.2307/j.ctt284vg8.11. 
Fourie, C. (2017). Who is experiencing what kind of moral distress? Distinctions for moving from a narrow to a broad definition of moral distress. AMA Journal of Ethics, 19(6), 578-584. https://doi.org/ 10.1001/journalofethics.2017.19.6.nlit1-1706.

Greenberg, N., Docherty, M., Gnanapragasam, S., \& Wessely, S. (2020). Managing mental health challenges faced by healthcare workers during Covid-19 pandemic. BMJ: British Medical Journal (Online), 368, m1211. https://doi.org/10.1136/bmj.m1211.

Halbesleben, J. R. (2006). Patient reciprocity and physician burnout: What do patients bring to the patient-physician relationship? Health Services Management Research, 19(4), 215-222. https://doi. org/10.1258/095148406778951493.

Jameton, A. (1984). Nursing practice: The ethical issues. Prentice-Hall.

Lamberson, B. (2016). What is Moral Distress? An overview. National Association of Catholic Chaplains. Retreived March 24, 2021, from https://www.nacc.org/vision/2016-mar-apr/what-is-moraldistress-an-overview/.

Mamun, M., \& Griffiths, M. (2020). First COVID-19 suicide case in Bangladesh due to fear of COVID19 and xenophobia: Possible suicide prevention strategies. Asian Journal of Psychiatry, 51, 102073. https://doi.org/10.1016/j.ajp.2020.102073.

Mendelson, T. (2013). Stress, emotional. In M. D. Gellman \& J. R. Turner (Eds.), Encyclopedia of behavioral medicine. New York: Springer. https://doi.org/10.1007/978-1-4419-1005-9_289.

Meulen, R. (2018). Solidarity and justice in health and social care. Cambridge University Press.

McCarthy, J., \& Deady, R. (2008). Moral distress reconsidered. Nursing Ethics, 15(2), 254-262. https:// doi.org/10.1177/0969733007086023.

Prainsack, B., \& Buyx, A. (2017). Solidarity in biomedicine and beyond. Cambridge University Press.

Pellegrino, E., \& Thomasma, D. (1988). For the patient's good: The restoration of beneficence in health care. Oxford University Press.

Roycroft, M., Wilkes, D., Pattani, S., Fleming, S., \& Olsson-Brown, A. (2020). Limiting moral injury in healthcare professionals during the COVID-19 pandemic. Occupational Medicine, 70(5), 312-314. https://doi.org/10.1093/occmed/kqaa087.

Rushton, C. (2015). Moral resilience: A capacity for navigating moral distress in critical care. $A A C N$ Advanced Critical Care, 27(1), 111-119.

Rushton, C. H. (2016). Moral resilience: A capacity for navigating moral distress in critical care. AACN Advanced Critical Care, 27(1), 111-119.

Rushton, C., Doerries, B., Greene, J., \& Geller, G. (2020). Dramatic interventions in the tragedy of the COVID-19 pandemic. The Lancet (British Edition), 306(10247), 305-306 https://doi.org/10.1016/ S0140-6736(20)31641-X.

Sulmasy, D. P. (2020). Principled decisions and virtuous care: An ethical assessment of the SIAARTI guidelines for allocating intensive care resources. Minerva Anestesiologica, 86(8), 872-876. https:// doi.org/10.23736/S0375-9393.20.14691-1.

Ter Meulen, R. (2016). Solidarity, justice, and recognition of the other. Theoretical Medicine and Bioethics, 37(6), 517-529. https://doi.org/10.1007/s11017-016-9387-3.

Ulrich, C., \& Grady, C. Eds. (2018). Moral distress in the health professions. Dordrecht: Springer International Publishing. https://doi.org/10.1007/978-3-319-64626-8.

United States Conference of Catholic Bishops (USCCB). (2020). USCCB Statements on COVID19. Retreived March 24, 2021, from https://www.usccb.org/news/2020/usccb-statements-coron avirus-covid-19.

Velazquez, M., Andre, C., Shanks, T., Meyer, M. (2018). The common good. Retreived March 24, 2021, from https://www.scu.edu/ethics/ethics-resources/ethical-decision-making/the-common-good/.

Willis, M. (2015). Moral decisions, moral distress, and the psychological health of nurses. Available at:https://www.researchgate.net/publication/272795333_Moral_decisions_moral_distress_and_the_ psychological_health_of_nurses. Accessed 28 July 2020.

Zhang, S., Wang, Y., Rauch, A., \& Wei, F. (2020). Unprecedented disruption of lives and work: Health, distress and life satisfaction of working adults in China one month into the COVID-19 outbreak. Psychiatry Research, 288:112958. https://doi.org/10.1016/j.psychres.2020.112958.

Publisher's Note Springer Nature remains neutral with regard to jurisdictional claims in published maps and institutional affiliations. 